\title{
A bibliometric analysis on the solid waste-related research from 1982 to 2013 in Iran
}

\author{
Alireza Mesdaghinia ${ }^{1,2} \cdot$ Amir Hossein Mahvi $^{2,3} \cdot$ Simin Nasseri ${ }^{1,2}$. \\ Ramin Nabizadeh Nodehi ${ }^{2} \cdot$ Mahdi Hadi ${ }^{1}$
}

Received: 24 August 2014/ Accepted: 23 April 2015/Published online: 8 May 2015

(C) The Author(s) 2015. This article is published with open access at Springerlink.com

\begin{abstract}
Background A bibliometric analysis was used to assess the trend of solid waste-related publications produced by Iran and indexed in Scopus from 1982 to 2013. The study aims to analyze the distribution of languages, countries, institutes, journals, author keywords, authorship pattern and co-authorship relationships.

Results The publication outputs showed an exponential trend $\left(R^{2}=0.98\right)$ and increased by $45.3 \%$ per year from 1982 to 2011 . It was received with a decreasing trend to 44 papers at the end of 2013. Journal of Environmental Studies published the most papers. University of Tehran (25\%), Islamic Azad University (8.24\%), Tehran University of Medical Sciences (7.35\%) played active roles in the publication and Abduli MA was the most productive author $(9.12 \%)$ in this field. The English language was dominant language of all publications $(88.24 \%)$. The appearance of keywords namely "Heavy metals", "landfill leachate" and "site selection" reveals the importance of release of heavy metals through landfill leachates and site selection issues in Iran.

Conclusions A downward trend in the number of publications is likely to be continued in future years. The highest
\end{abstract}

Mahdi Hadi

hadi_rfm@yahoo.com

1 Center for Water Quality Research (CWQR), Institute for Environmental Research (IER), Tehran University of Medical Sciences, Tehran, Iran

2 Department of Environmental Health, School of Public Health, Tehran University of Medical Sciences, Tehran, Iran

3 Center for Solid Waste Research (CSWR), Institute for Environmental Research (IER), Tehran University of Medical Sciences, Tehran, Iran cooperation was found among the capital universities in Iran and other institutions had a minor role in the production of articles. It is hoped that transferring the experiences by main universities and starting up teamwork activities may increase the number of researches in this field. It is expected that this study could be the basis for a better understanding of development of researches related to solid waste in Iran.

Keywords Solid waste - Iran - Bibliometric analysis . Scopus

\section{Introduction}

The attention to the solid waste-related problems is paid by large amount of scientific articles originated from many countries around the world (Fu et al. 2010). So far, numerous studies have been conducted in the field of solid waste management and engineering in Iran. In one of the earliest studies in this field, Chokouhmand (1982) studied the energy recovery by incineration of municipal solid waste. He established a laboratory to obtain the physical and chemical compositions of the solid waste and analyzed the amount of collected solid waste data. The practical aspects associated with solid waste management systems in Tehran (the capital of Iran) such as equipment management, personnel, organizational structure, financing, cost accounting and budgeting were described by Abduli (Abduli 1995). The status of industrial waste management in the capital of Iran and the principle guidelines and policies regarding the collection, handling and safe disposal were also assessed by Abduli (Abduli 1996). In the recent years, municipal solid waste (MSW) has been one of the most important environmental concerns throughout Iran's 
regions and universities and research institutes around the country have produced several publications in this field. Assessing the research trend, identification of the most influential research institutions, authors, journals, and the collaboration between universities and between authors, in the field of solid waste management and technology, may help relevant researchers to realize the scope of solid waste more carefully and establish the further research direction in Iran.

The bibliometric methods have been used commonly in many disciplines of science and engineering to study the scientific production and research trends (Fu et al. 2013, 2014; Ho 2014; Tan et al. 2014). Fu et al. (2010) evaluated the distribution pattern of the publications of solid waste researches from 1993 to 2008. Today many studies have been conducted by focusing on the solid waste management and engineering but the trend of researches in the field of solid waste has not been studied yet in Iran. Thus, a systematic gathering and analyzing data to get a panoramic look at the solid waste researches is necessary to be conducted in Iran.

This study aims to find the most important authors in this field and to assess the interaction between universities and authors around the country. The bibliometric methods often evaluate the trend of the research by publication outputs of countries, research institutes, journals, and the research field analysis (Braun et al. 1995; Colman et al. 1995; Ugolini et al. 1997). The analysis of the author keywords, languages and co-authorship pattern are also going to be conducted in this study.

A research tool utilized by bibliometric practitioners includes the use of Scopus, a bibliographic database containing the abstracts and citations for academic journal articles. Scopus is owned by Elsevier B.V. Company (Elsevier B.V. Company 2014) and in this study the bibliometric data were based on the Scopus bibliographic database.

In this study, all solid waste-related researches produced during 1982-2013, indexed by Scopus, were analyzed by emphasizing on the article production, keywords analysis, authorship pattern analysis, co-authorship networks mapping, the distribution of countries, institutes, authors, journals, subject areas and languages, to provide a more comprehensive and complete assessment of the solid waste-related researches in Iran.

\section{Methods}

The data was based on the Scopus bibliographic database. Scopus is a database containing abstracts and citations for academic journal articles. It covers nearly 21,000 titles from over 5000 publishers, of which 20,000 are peer- reviewed journals in the scientific, technical, medical, and social sciences (including arts and humanities) (Elsevier B.V. Company 2014). Scopus offers about $20 \%$ more coverage than Web of Science, whereas Google Scholar offers results of inconsistent accuracy (Falagas et al. 2008). In this study for bibliometric analysis, the Scopus was searched on 15 March 2014 with a search script (presented in "Appendix") to compile the bibliography of all publications related to the solid waste researches conducted in Iran.

The final number of publications fulfilling the search script criteria was 407 . The collaboration type was determined by assessing the addresses of the authors. The term "Single Country" (SC) was assigned if the all authors of paper were from the same country and the term "Multiple Country" (MC) was assigned if the article was co-authored by researchers from different countries. The term "Single Institute" (SI) was assigned if researchers were from the same institute and the term "Multiple Institute" (MI) was assigned if the article was co-authored by researchers from different institutes. Collaboration type was also assessed in term of the names of authors. The term "Single Author" (SA) was assigned if the publication was produced by one author and the term "Multiple Author" (MA) was assigned the article was co-authored by at least two researchers (Chiu and Ho 2005).

In this study all articles referring to the researches on the solid waste, during the past 31 years (1982-2013), were assessed in term of following aspects: distribution of languages and publication year, distribution of countries, coauthorship relations among countries, distribution of journals and subject categories, distribution of author keywords, distribution analysis of authors and institutions, authorship pattern analysis and co-authorship relations among authors. All analyses referring to the document type, language, journal, country, institutes and author were performed using R programming language v.3.0.2 (R Core Team 2013). The VOSviewer v.1.5.5 was used for constructing and viewing bibliometric maps.

\section{Results and discussion}

In all publications met the search criteria ("Appendix"), four document types were included. The journal articles (published or in-press) were the most frequently used document type $(340 ; 83.54 \%)$. The three other types were the conference papers $(51 ; 12.53 \%)$, review papers $(14$; $3.44 \%)$ and book chapters $(2 ; 0.49 \%)$. Because journal articles are peer-reviewed within this field and were dominant among the document types, only journal articles were selected for further analysis and all others were discarded. There was no marked change in the number of 


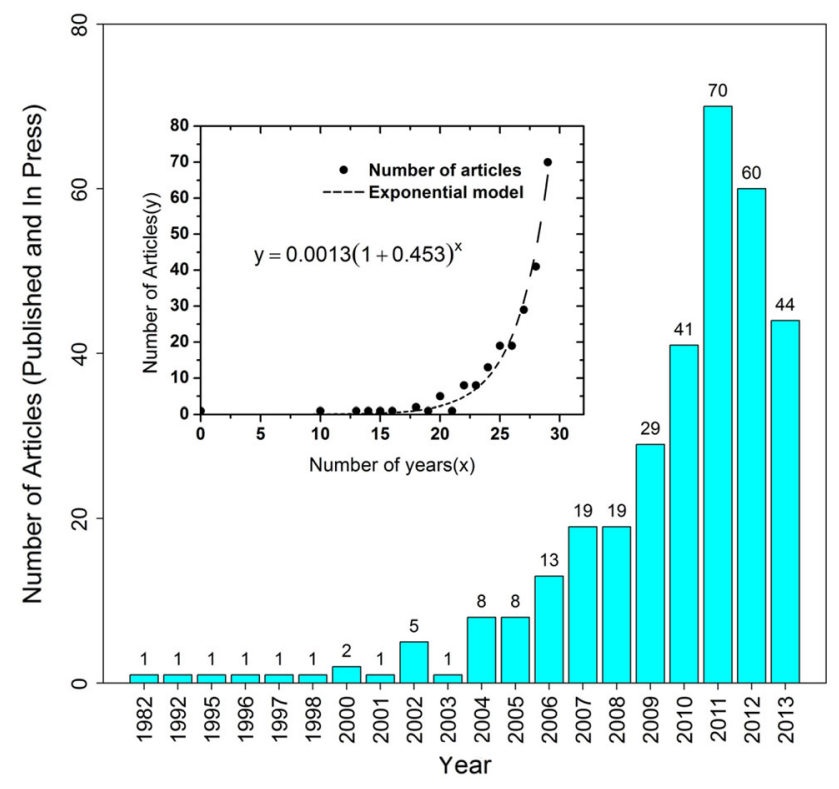

Fig. 1 Annual journal articles publication

conference papers during the period from 1977 to 2013 . The distribution of annual journal article publications is shown in Fig. 1. A significant decreasing trend in the number of research articles from 2011 to 2013 is notable. It is obvious that there was a significant exponential increasing trend $\left(R^{2}=0.98\right)$ in the number of article publications and they were increased by $45.3 \%$ per year during the period from 1982 to 2011. From Fig. 1 it can be seen that the number of articles in this period increased from one paper in 1982 to 70 papers in 2011 and then received with a downward trend to 44 papers at the end of 2013. This sudden downward trend in the number of articles started in 2011, is likely to continue in the future. Given the importance of environmental issues and solid waste management in Iran, the policy makers must take some supportive actions to hinder this downward trend in the number of the research publications in this area of science.

In bibliometric analysis, it is important to note the language of publication. The Analysis of the language distribution revealed that the English was the predominant language of articles on solid waste-related studies from 1982 to 2013 in Iran. Out of the 340 records, English was occupied the first position with 300 article records $(88.24 \%)$. There were four other languages in addition to English, which were Persian (27; $7.94 \%)$, Arabic (6; 1.76), Persian and English (6; $1.76 \%$ ), English and Spanish (1;0.29\%). Therefore, the English language is the main language of article publications. English language is the dominant language in bibliometrics because it is official language in many countries and many articles and conference proceedings are published in English language only (Patra et al. 2006). The scientific bibliometric studies conducted so far (Fu et al. 2010; Ma et al. 2011; Yang et al. 2013), revealed that the English language is the predominant language of the publications in the field of solid waste.

The contribution analysis of the co-countries publications was based on journal articles in which the address and affiliation of at least one author were provided. Out of 340 articles that Iran are involved, $280(82.35 \%)$ were independent papers produced by Iran and 60 papers $(17.65 \%)$ were internationally collaborative publications between Iran and other countries (Table 1). Nineteen countries were

Table 1 Most productive institutions in research on solid waste from 1982 to 2013

\begin{tabular}{|c|c|c|c|c|c|}
\hline Institute & $\mathrm{TP}(\%) \mathrm{R}$ & $\mathrm{SI}(\%) \mathrm{R}$ & $\mathrm{MI}(\%) \mathrm{R}$ & $\mathrm{SI}_{\mathrm{P}}$ & $\mathrm{MI}_{\mathrm{P}}$ \\
\hline University of Tehran & $85(25) 1$ & $42(27.27) 1$ & $43(23.12) 1$ & 49.41 & 50.59 \\
\hline Islamic Azad University/Science and Research Branch & $28(8.24) 2$ & $5(3.25) 4$ & $23(12.37) 2$ & 17.86 & 82.14 \\
\hline Tehran University of Medical Sciences & $25(7.35) 3$ & $7(4.55) 2$ & $18(9.68) 4$ & 28 & 72 \\
\hline Tarbiat Modares University & $24(7.06) 4$ & $5(3.25) 4$ & $19(10.22) 3$ & 20.83 & 79.17 \\
\hline Iran University of Science and Technology & $18(5.29) 5$ & $5(3.25) 4$ & $13(6.99) 5$ & 27.78 & 72.22 \\
\hline Isfahan University of Technology & $15(4.41) 6$ & $7(4.55) 2$ & $8(4.3) 6$ & 46.67 & 53.33 \\
\hline Amirkabir University of Technology & $11(3.24) 7$ & $3(1.95) 10$ & $8(4.3) 6$ & 27.27 & 72.73 \\
\hline Shiraz University & $10(2.94) 8$ & $2(1.3) 16$ & $8(4.3) 6$ & 20 & 80 \\
\hline Toosi University of Technology & $9(2.65) 9$ & $5(3.25) 4$ & $4(2.15) 18$ & 55.56 & 44.44 \\
\hline Isfahan University of Medical Sciences & $8(2.35) 10$ & $3(1.95) 10$ & $5(2.69) 11$ & 37.5 & 62.5 \\
\hline University of Guilan & $8(2.35) 10$ & $5(3.25) 4$ & $3(1.61) 25$ & 62.5 & 37.5 \\
\hline University of Kurdistan & $8(2.35) 10$ & $1(0.65) 24$ & $7(3.76) 9$ & 12.5 & 87.5 \\
\hline Ferdowsi University of Mashhad & $7(2.06) 13$ & $2(1.3) 16$ & $5(2.69) 11$ & 28.57 & 71.43 \\
\hline Iran University of Medical Sciences & $7(2.06) 3$ & $0(0) 59$ & $6(3.23) 10$ & 0 & 85.71 \\
\hline Sharif University of Technology & $7(2.06) 13$ & $3(1.95) 10$ & $4(2.15) 18$ & 42.86 & 57.14 \\
\hline
\end{tabular}

$T P$ Total publication, $R$ Rank, MA Multiple author publications, $S A$ Single author publications, $S A_{P}$ Percent of Single author publication of the total publications, $M A_{P}$ Percent of multiple author publications of the total publications 
involved in the production of articles with Iran. The Malaysia contributes to produce of $5.88 \%$ of total article publications (TP) or $33 \%$ of the total articles were produced by international collaboration (MC). The United States is the second country has cooperated with Iran in the production of $3.24 \%$ of total article publications (18.33\% of internationally collaborative publications) in the field of solid waste. The Canada (2.94\% TP and $16.67 \% \mathrm{MC}$ ) and Germany ( $1.18 \% \mathrm{TP}$ and $6.67 \% \mathrm{MC})$ were ranked third and fourth in terms of being involved in the producing of papers with Iran.
The top 15 institutes within 31 years period are displayed in Table 1. Tehran University ranked first among all institutes. Out of 340 articles, 85 (25\%) articles produced by Tehran University. $50.59 \%$ of this university's publications produced by inter-institute collaboration and the rest $(49.41 \%)$ independently. $27.27 \%$ of all "single institute" publications (154 articles) and $23.12 \%$ of all "inter-institute publications" (186 articles) were attributed to the University of Tehran. Islamic Azad University (Science and Research Branch), Tehran University of Medical Sciences and Tarbiat Modares University with 28
Table 2 Most productive authors with at least 4 papers in research on solid waste from 1982 to 2013

\begin{tabular}{|c|c|c|c|c|c|}
\hline Author & $\mathrm{TP}(\%) \mathrm{R}$ & MA (\%) R & $\mathrm{SA}(\%) \mathrm{R}$ & $\mathrm{SA}_{\mathrm{P}}$ & $\mathrm{MA}_{\mathrm{P}}$ \\
\hline Abduli MA & $31(9.12) 1$ & $28(8.81) 1$ & $3(13.64) 1$ & 9.68 & 90.32 \\
\hline Safari E & $9(2.65) 2$ & 7 (2.2) 3 & $2(9.09) 2$ & 22.22 & 77.78 \\
\hline Shariatmadari N & $9(2.65) 2$ & $9(2.83) 2$ & 0 (0) 17 & 0 & 100 \\
\hline Mehrdadi N & $7(2.06) 4$ & 7 (2.2) 3 & $0(0) 17$ & 0 & 100 \\
\hline Nabizadeh $\mathrm{R}$ & $7(2.06) 4$ & 7 (2.2) 3 & 0 (0) 17 & 0 & 100 \\
\hline Naddafi K & $7(2.06) 4$ & 7 (2.2) 3 & 0 (0) 17 & 0 & 100 \\
\hline Farzadkia M & $6(1.76) 7$ & $6(1.89) 7$ & 0 (0) 17 & 0 & 100 \\
\hline Noori $\mathrm{R}$ & $6(1.76) 7$ & $6(1.89) 7$ & $0(0) 17$ & 0 & 100 \\
\hline Sabour MR & $6(1.76) 7$ & $6(1.89) 7$ & 0 (0) 17 & 0 & 100 \\
\hline Jaafarzadeh N & 5 (1.47) 10 & 5 (1.57) 10 & $0(0) 17$ & 0 & 100 \\
\hline Karbassi AR & 5 (1.47) 10 & 5 (1.57) 10 & $0(0) 17$ & 0 & 100 \\
\hline Mosaferi M & 5 (1.47) 10 & 5 (1.57) 10 & 0 (0) 17 & 0 & 100 \\
\hline Olfati JA & 5 (1.47) 10 & 5 (1.57) 10 & $0(0) 17$ & 0 & 100 \\
\hline Torabian A & 5 (1.47) 10 & 5 (1.57) 10 & 0 (0) 17 & 0 & 100 \\
\hline Abbasi M & $4(1.18) 15$ & $4(1.26) 15$ & 0 (0) 17 & 0 & 100 \\
\hline Ahmadi M & $4(1.18) 15$ & $4(1.26) 15$ & 0 (0) 17 & 0 & 100 \\
\hline Alidadi $\mathrm{H}$ & $4(1.18) 15$ & $4(1.26) 15$ & 0 (0) 17 & 0 & 100 \\
\hline Ashori A & $4(1.18) 15$ & $3(0.94) 34$ & $1(4.55) 6$ & 25 & 75 \\
\hline Badv K & $4(1.18) 15$ & $4(1.26) 15$ & 0 (0) 17 & 0 & 100 \\
\hline Baghvand A & $4(1.18) 15$ & $4(1.26) 15$ & $0(0) 17$ & 0 & 100 \\
\hline Bahmanyar MA & $4(1.18) 15$ & $4(1.26) 15$ & $0(0) 17$ & 0 & 100 \\
\hline Ghiasinejad H & $4(1.18) 15$ & $4(1.26) 15$ & $0(0) 17$ & 0 & 100 \\
\hline Jalili GM & $4(1.18) 15$ & $4(1.26) 15$ & $0(0) 17$ & 0 & 100 \\
\hline Jorfi S & $4(1.18) 15$ & $4(1.26) 15$ & $0(0) 17$ & 0 & 100 \\
\hline Kalbasi M & $4(1.18) 15$ & $4(1.26) 15$ & $0(0) 17$ & 0 & 100 \\
\hline Mahvi AH & $4(1.18) 15$ & $4(1.26) 15$ & $0(0) 17$ & 0 & 100 \\
\hline Moharamnejad N & $4(1.18) 15$ & $4(1.26) 15$ & $0(0) 17$ & 0 & 100 \\
\hline Monavari SM & $4(1.18) 15$ & $4(1.26) 15$ & $0(0) 17$ & 0 & 100 \\
\hline Nasseri $\mathrm{S}$ & $4(1.18) 15$ & $4(1.26) 15$ & $0(0) 17$ & 0 & 100 \\
\hline Nourbakhsh F & $4(1.18) 15$ & $3(0.94) 34$ & $1(4.55) 6$ & 25 & 75 \\
\hline Peyvast G & $4(1.18) 15$ & $4(1.26) 15$ & $0(0) 17$ & 0 & 100 \\
\hline Taghipour $\mathrm{H}$ & $4(1.18) 15$ & $4(1.26) 15$ & $0(0) 17$ & 0 & 100 \\
\hline Yaghmaeian $\mathrm{K}$ & $4(1.18) 15$ & $4(1.26) 15$ & $0(0) 17$ & 0 & 100 \\
\hline Yousefi Z & $4(1.18) 15$ & $4(1.26) 15$ & $0(0) 17$ & 0 & 100 \\
\hline Zazouli MA & $4(1.18) 15$ & $4(1.26) 15$ & $0(0) 17$ & 0 & 100 \\
\hline
\end{tabular}

$T P$ Total publication, $R$ Rank, $M A$ Multiple author publications, $S A$ Single author publications, $S A_{P}$ Percent of Single author publication of the total publications, $M A_{P}$ Percent of multiple author publications of the total publications 
$(8.24 \%), 25(7.35 \%)$ and $24(7.06 \%)$ publications were ranked second to forth, respectively. $72 \%$ of the publications of Tehran University of Medical Sciences were published by inter-institute collaboration. Among these four top institutes, the Islamic Azad University (Science and Research Branch) is only university that produced the highest percentage $(82.14 \%)$ of its published articles through inter-institute collaborations.

Table 2 shows the productive authors identified with at least four publications. Abduli MA from the Faculty of the Environment of the University of Tehran is the most productive author in this field with 31 publications, which account about $9.12 \%$ of the total article publications. Out of his 31 publications, $28(90.32 \%)$ and $3(9.68 \%)$ were "MA" and "SA" publications, respectively. $13.64 \%$ of all single author publications (22 articles) and $8.81 \%$ of all multiple authors publications (318 articles) were produced by Abduli MA. Two authors, Safari E and Shariatmadari N, ranked in the second position with nine publications. Mehrdadi N, Nabizadeh R and Naddafi $\mathrm{K}$ ranked in the third position with seven publications. These six top authors produced about $20 \%$ of total publications in the solid waste field.

The distribution analysis of the journals showed that the journals namely Journal of Environmental Studies, Waste Management and Research, Waste Management and International Journal of Environmental Research with 34 $(10 \%), 23(6.76 \%), 17(5 \%)$ and $17(5 \%)$ publications, respectively, were the top journals each produced more than 10 publications on the field of solid waste. The distribution analysis of the subject categories also indicates that "environmental sciences", "Agricultural and Biological Sciences", "Medicine", "Engineering", "Earth and Planetary Sciences" and "Chemistry" are the top six most popular subject categories which have involved 197 (57.94\%), 75 (22.06\%), 31 (9.12\%), 29 (8.53\%), 21 $(6.18 \%)$ and $20(5.88 \%)$ of the total article publications, respectively.

The bibliometric methods concerning author keywords analysis in a specific period, could be found in recent years (Chiu and Ho 2007; Ho 2007). The useful information about the trend of researches that are concerned by researchers could be provided by analyzing the author keywords. The statistical analysis of author keywords might be aimed at discovering directions of science, and proved to be important for monitoring development of science (Hu et al. 2010). The assessment of author keywords in this study period revealed that 500 author keywords were used. Among them, $338(67.60 \%)$ keywords appeared only once, 94 (18.80\%) keywords appeared twice, 25 (5\%) keywords appeared thrice and only 43 author keywords (8.6\%) were used more than three times. The large number of once-only author keywords probably indicated a lack of continuity in research and a wide disparity in research focuses (Chuang et al. 2007). Table 3 shows top 20 most frequently used author keywords appeared in articles on the solid wasterelated studies from 1982 to 2013. Except for eight top keywords, which were searching keywords in this study, the two frequently used keywords were "Heavy metals" and "Site selection". The appearance of keyword "Heavy

Table 3 Top 20 keywords used by the authors

\begin{tabular}{lll}
\hline Keyword & TP (\%) & R \\
\hline Landfill & $29(8.53)$ & 1 \\
Municipal solid waste & $28(8.24)$ & 2 \\
Solid waste & $26(7.65)$ & 3 \\
Leachate & $25(7.35)$ & 4 \\
Iran & $23(6.76)$ & 5 \\
Compost & $19(5.59)$ & 6 \\
Management & $13(3.82)$ & 7 \\
Waste management & $13(3.82)$ & 7 \\
Heavy metals & $13(3.82)$ & 7 \\
Environment & $12(3.53)$ & 10 \\
Landfill leachate & $10(2.94)$ & 11 \\
Tehran & $8(2.35)$ & 12 \\
Site selection & $8(2.35)$ & 12 \\
Vermicompost & $8(2.35)$ & 12 \\
Composting & $8(2.35)$ & 12 \\
Hazardous waste & $7(2.06)$ & 16 \\
GIS & $7(2.06)$ & 16 \\
Municipal solid waste compost & $7(2.06)$ & 16 \\
Biosolids & $7(2.06)$ & 16 \\
Solid waste management & $7(2.06)$ & 16 \\
\hline
\end{tabular}

$T P$ Total publication, $R$ Rank

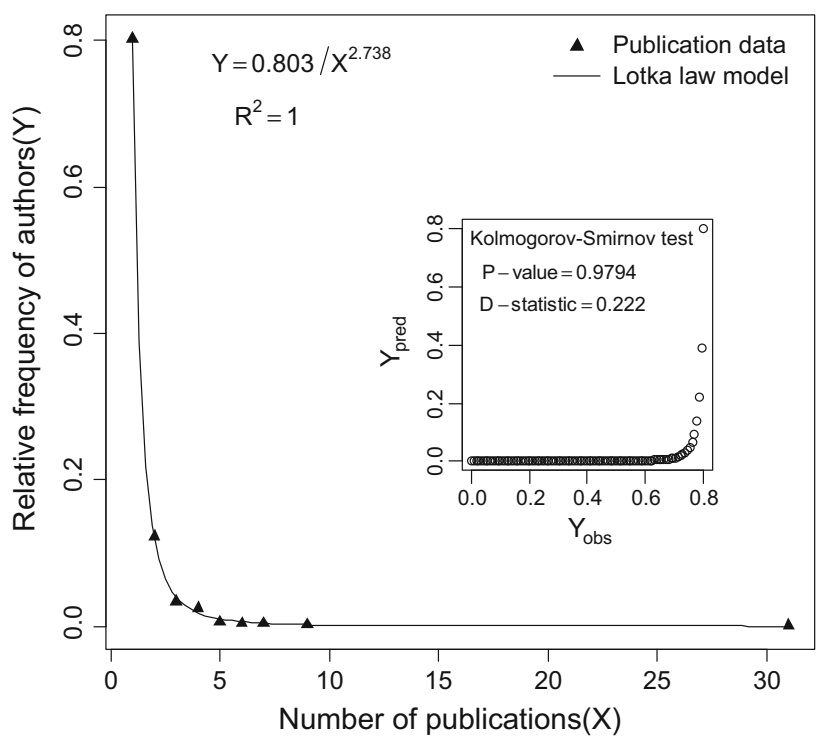

Fig. 2 Relative frequency of authors versus the number publications 
metals" reveals the importance of release of heavy metals to environment from solid waste especially through landfill leachates. This is a concern that has been investigated in $3.82 \%$ of articles. Given the importance of an appropriate selection of disposal site that is one of the major problems in waste management in Iran, "Site selection" is another keyword that appeared in $2.35 \%$ of studied articles.

Table 4 Authorship pattern

\begin{tabular}{lrll}
\hline$X$ & No. of authors & $Y$ & $Y_{\text {Lotka }}$ \\
\hline 1 & 688 & 0.802 & 0.802 \\
2 & 105 & 0.122 & 0.120 \\
3 & 29 & 0.033 & 0.039 \\
4 & 21 & 0.024 & 0.018 \\
5 & 5 & 0.005 & 0.009 \\
6 & 3 & 0.003 & 0.005 \\
7 & 3 & 0.003 & 0.003 \\
9 & 2 & 0.002 & 0.001 \\
31 & 1 & 0.001 & 0.000 \\
\hline
\end{tabular}

According to the publication data, it was revealed that 857 authors publish 340 articles, thus there is about 0.39 articles per author. It is clear that single authorship is common in this field. The numbers of $688(80.28 \%)$ authors have only one publication and $105(12.25 \%)$ authors have two publications. On the other hand, only one author produced the maximum numbers of publications (31 articles). The relationship between the relative frequency of authors and their corresponding publications is shown in Fig. 2. The Lotka's (1926) law, an inverse square law, describes the frequency of publication by authors in any given field. It states that "the number of authors making $n$ contributions is about $1 / n^{\mathrm{a}}$ of those making one; and the proportion of all contributors, that make a single contribution, is about 60 percent". This means that out of all the authors in a given subject field, about $60 \%$ publish only one article, $15 \%$ publish two articles, $7 \%$ publish three articles, and so on. According to Lotka's law of scientific productivity, only six percent of the authors in a given field will produce more than 10 articles. The generalized form of Lotka's Law can be expressed as:
Fig. 3 Bibliometric network map of the co-occurrence of the authors

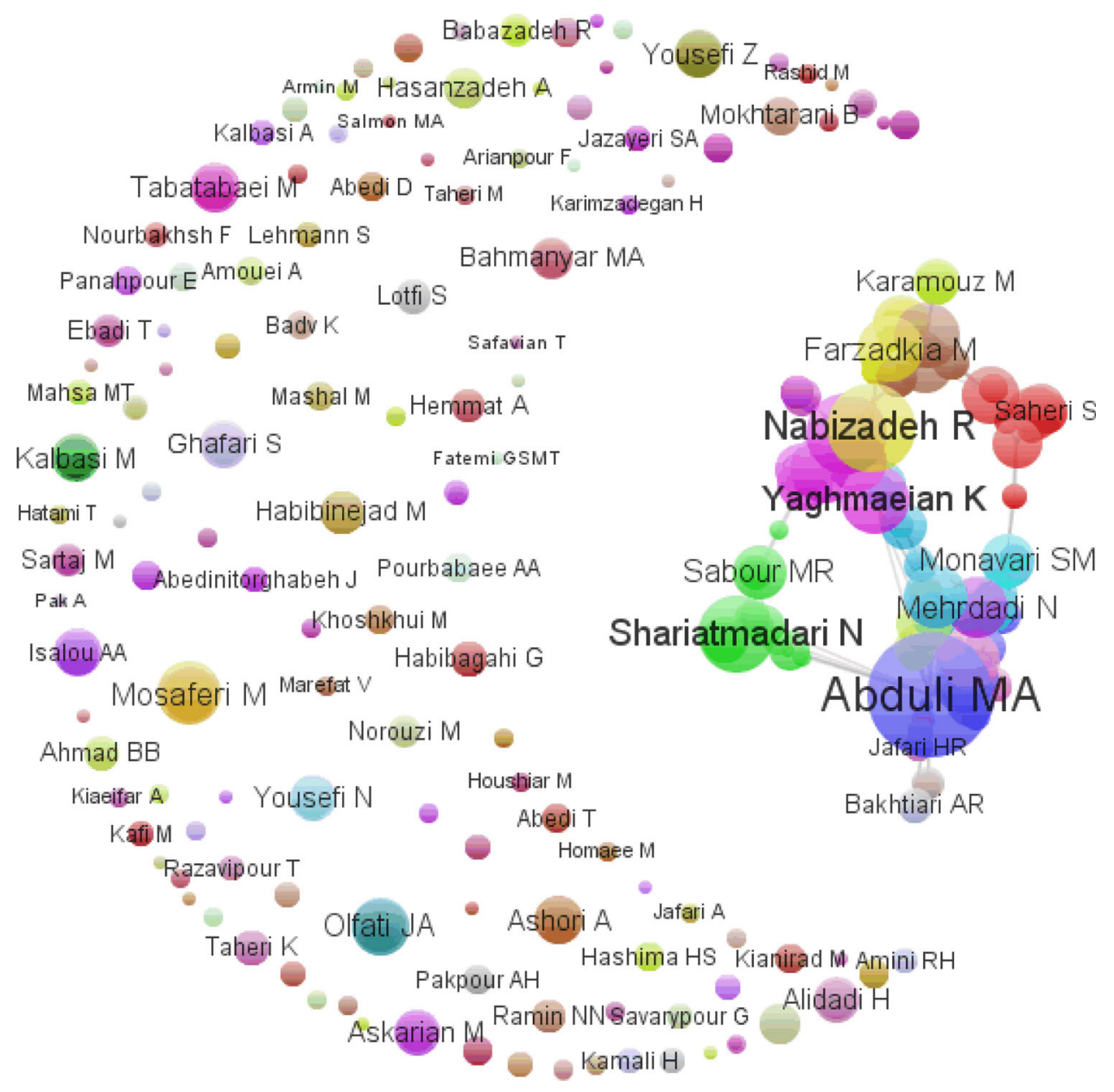


$Y=\frac{C}{X^{n}}$

where $Y$ is the relative frequency of authors with $\mathrm{X}$ articles, the exponent $n$ and constant $C$ are parameters to be estimated from a given set of author productivity data.

Table 5 Author names with at least 3 co-authored publications

\begin{tabular}{|c|c|c|c|}
\hline Author 1 & Author 2 & $\mathrm{TP}(\%)$ & \\
\hline Mosaferi M & Taghipour $\mathrm{H}$ & $4(1.18)$ & 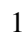 \\
\hline Olfati JA & Peyvast $\mathrm{G}$ & $4(1.18)$ & 1 \\
\hline Abduli MA & Noori $\mathrm{R}$ & $4(1.18)$ & 1 \\
\hline Abduli MA & Baghvand A & $4(1.18)$ & 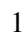 \\
\hline Karimpourfard M & Shariatmadari N & $3(0.88)$ & 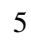 \\
\hline Ashori A & Hamzeh Y & $3(0.88)$ & 3 \\
\hline Ghanbarzadeh LM & Sabour MR & $3(0.88)$ & 3 \\
\hline Alidadi $\mathrm{H}$ & Najafpoor AA & $3(0.88)$ & s \\
\hline Mokhtarani B & Mokhtarani N & $3(0.88)$ & s \\
\hline Nabizadeh $\mathrm{R}$ & Naddafi K & $3(0.88)$ & \\
\hline Bahmanyar MA & Pirdashti $\mathrm{H}$ & $3(0.88)$ & \\
\hline Nabizadeh $\mathrm{R}$ & Yaghmaeian K & $3(0.88)$ & \\
\hline Nabizadeh $\mathrm{R}$ & Yunesian M & $3(0.88)$ & \\
\hline Koolivand A & Yunesian M & $3(0.88)$ & \\
\hline Naddafi K & Yaghmaeian K & $3(0.88)$ & \\
\hline Koolivand A & Nabizadeh R & $3(0.88)$ & 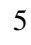 \\
\hline Machado SL & Shariatmadari N & $3(0.88)$ & 5 \\
\hline Abbasi M & Abduli MA & $3(0.88)$ & 5 \\
\hline Abduli MA & Safari E & $3(0.88)$ & 5 \\
\hline Jafari AJ & Nabizadeh R & $3(0.88)$ & 5 \\
\hline Jafari AJ & Koolivand A & $3(0.88)$ & 5 \\
\hline Jafari AJ & Yunesian M & $3(0.88)$ & 5 \\
\hline Karimpourfard M & Machado SL & $3(0.88)$ & 5 \\
\hline Yousefi Z & Zazouli MA & $3(0.88)$ & \\
\hline
\end{tabular}

$T P$ Total publication, $R$ Rank
Using above formula and the modifications given by Pao, Fang (Fang and Fang 1995; Nicholls 1986; Pao 1985) the values of $\mathrm{C}$ and $\mathrm{n}$ for the solid waste-related researches in Iran were determined to be 0.803 and 2.738 , respectively. The Kolmogorov-Smirnov Goodness-of-Fit test shows that the literature does follow Lotka's law ( $P$ value $=0.979$ ). It was found that for this study the maximum (absolute) deviation is 0.222 , leading to the acceptance of the Lotka's law. Figure 2 shows the observed and theoretical relative frequencies of authors $(Y)$ versus the number of corresponding publications $(X)$. Table 4 shows the observed $(Y)$ and theoretical $\left(Y_{\text {Lotka }}\right)$ relative frequencies of authors and the number of corresponding publications.

Bibliometric mapping of co-authorship relations among authors allows for the representation of information in ways, which make relationships among them easier to understand. Figure 3 shows a co-occurrence network map generated from publications of the authors. Several different components including author nodes (circles), co-occurrence weight (circle size), networked relationship clustering (color and proximity), and name of authors (text) are included in a map. The paper co-authorship network is a network expressing existence of co-authorship relation between authors of scientific papers (Van Eck and Waltman 2011).

In Fig. 3 the circle's color indicates the cluster or group which the authors are associated. Clustering shows the dimension of similarity to other authors in the display. The co-authorship relations are relations representing whether an author have written a paper with another author. Typically, a paper is written by two or more authors. Analyzing co-authorship information on a larger database of scientific publications will assist in identifying groups of people who work closely together (Van Eck and Waltman 2011). The authors with at least three co-authored publications are shown in Table 5. The maximum number of co-

Table 6 Institute names with at least three co-instituted publications

\begin{tabular}{|c|c|c|c|}
\hline Institute 1 & Institute 2 & $\mathrm{TP}(\%)$ & $\mathrm{R}$ \\
\hline Islamic Azad University/Science and Research Branch & University of Tehran & $9(2.65)$ & 1 \\
\hline Tarbiat Modares University & University of Tehran & $5(1.47)$ & 2 \\
\hline Tarbiat Modares University & Tehran University of Medical Sciences & $4(1.18)$ & 3 \\
\hline Hamadan University of Medical Sciences & Tehran University of Medical Sciences & $3(0.88)$ & 4 \\
\hline Isfahan University of Medical Sciences & Mashhad University of Medical Sciences & $3(0.88)$ & 4 \\
\hline Islamic Azad University/Science and Research Branch & Sharif University of Technology & $3(0.88)$ & 4 \\
\hline Islamic Azad University/Science and Research Branch & Universiti Kebangsaan Malaysia & $3(0.88)$ & 4 \\
\hline Tehran University of Medical Sciences & University of Applied Science and Technology & $3(0.88)$ & 4 \\
\hline Iran University of Science and Technology & University of Tehran & $3(0.88)$ & 4 \\
\hline Federal University of Bahia & Iran University of Science and Technology & $3(0.88)$ & 4 \\
\hline Iranian Research Organization for Science and Technology & University of Tehran/Karaj & $3(0.88)$ & 4 \\
\hline Hamadan University of Medical Sciences & University of Applied Science and Technology & $3(0.88)$ & 4 \\
\hline
\end{tabular}

$T P$ Total publication, $R$ Rank 
Payame-Noor University/Khorams

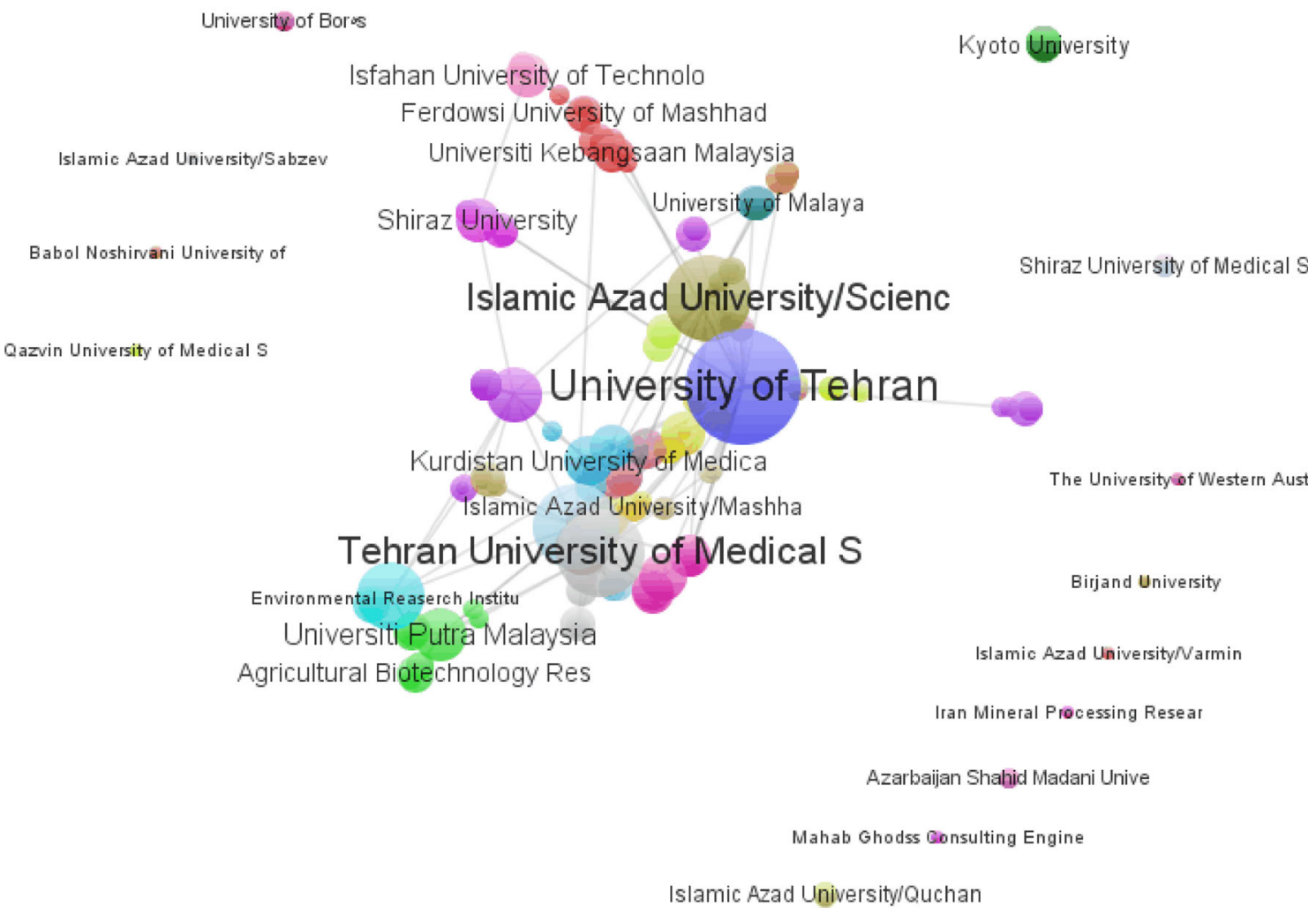

Fig. 4 Bibliometric network map of the co-occurrence of the institutions

authored publications per each pair of authors was four articles. Seven top authors in Table 5 involved in the production of $4.72 \%$ of total publications. In other words, each pair of authors, Mosaferi $\mathrm{M}$ and Taghipour H, Olfati JA and Peyvast G, Abduli MA and Noori R and Abduli $\mathrm{MA}$ and Baghvand $\mathrm{A}$, has been involved in the production of four articles $(1.18 \%)$. The mentioned pairs ranked first in terms of the number of co-authored publications.

Each circle in Fig. 3 is given a label derived from the name of author being analyzed. Visually, the size of the circles and labels show the co-occurrence weight. The authors, Abduli MA, Nabizadeh R, Naddafi K with 74, 37 and 31 co-occurrence weights, respectively, have most collaboration with other authors. The value of weight is the number of co-authored publications for each author. By default, for the authors with same co-occurrence weight, for example., Yaghmaeian K and Nasseri S, only one of them has been shown on the Fig. 3 to avoid overlapping author's names. Among all authors, Abduli MA with 74 cooccurrence weights published 31 papers. Thus, this author may be considered as the most influential author in the field of solid waste in Iran. This means, while Abduli MA produced the greatest number of papers, he has the most collaboration with other researchers.
Similar to what was shown for the case of authors, the Co-authorship relationships among the institutes can provide a useful representation of the relationships among the institutes and makes them easier to understand. Table 6 represents the names of the institutes with at least three coinstituted publications. The co-occurrence network map from the publications of these institutes is shown in Fig. 4 included the institution nodes, co-occurrence weight, networked relationship clustering, and the name of institutes. The institutions with at least three co-instituted publications are shown in Table 6. The Islamic Azad University (Science and Research Branch) with the University of Tehran have been involved in the production of nine articles $(2.65 \%)$. This pair ranked first in terms of the number of co-instituted publications.

Clustering methods have a long tradition in bibliometrics as tools for grouping bibliometric units on the basis of similarity properties measuring the distance between them (Callon et al. 1983). In Fig. 4 the similarity strength between institutes has been established, the institutes are represented as graph nodes and the similarity relationship between two institutes is represented as a weighted edge connecting them, where weights stand for the similarity intensity. Universities are colored based on the cluster to 
Table 7 Institutions with at least ten co-occurrences weights

\begin{tabular}{llc}
\hline Institute & Weight & Cluster \\
\hline University of Tehran & 66 & 3 \\
Tehran University of Medical Sciences & 38 & 16 \\
Islamic Azad University/Science and Research Branch & 36 & 9 \\
Tarbiat Modares University & 36 & 18 \\
Iran University of Science and Technology & 23 & 6 \\
Iran University of Medical Sciences & 15 & 11 \\
University of Kurdistan & 15 & 14 \\
Universiti Putra Malaysia & 14 & 2 \\
Kurdistan University of Medical Sciences & 12 & 7 \\
Bu-Ali Sina University & 11 & 13 \\
Isfahan University of Technology & 10 & 10 \\
Amirkabir University of Technology & 10 & 4 \\
Shiraz University & 10 & 5 \\
Ahvaz Jundishapur University of Medical Sciences & 10 & 7 \\
\hline
\end{tabular}

which they belong. As shown in Table 7 the most of universities with at least ten co-occurrences weights are belong to different clusters. In this way, universities that belong to the same cluster are very similar to each other, whereas universities belonging to different clusters are very different in term of bibliometric data. Each cluster is interpreted as providing a characterization of research activity by institutes, identifying both their strengths and weakness (Ibáñez et al. 2013). As is shown in Table 7 the University of Tehran with 66 co-occurrence weights have the most collaboration with other institutes. The weight parameter is the number of co-instituted publications for each institution. By default, for the institutions with same co-occurrence weights, for example., Islamic Azad University/Science and Research Branch and Tarbiat Modares University, only one of them has been shown in Fig. 4. Tehran University of Medical Sciences was ranked second with 38 co-occurrence weights.

\section{Conclusions}

To increase the understanding and to provide a clearer insight into the trend and contributions on the characteristics of the solid waste-related research activities in Iran, bibliometric methods were applied in this study. The results indicate that the number of annual article publications was increased by $45.3 \%$ per year during the period from 1982 to 2011, but then it was continued with a decreasing trend up to the end of 2013 (37\% reduction). It may be a concern because this downward trend in the number of publications is likely to continue in future years. University of Tehran, Islamic Azad University (Science and Research Branch) and Tehran University of Medical Sciences as three main universities in the capital of Iran (Tehran) were the most productive universities with $25,8.24$ and $7.35 \%$ of total article publications, respectively. Based on this finding, major research activities on the field of solid waste in Iran have been conducted by the universities mainly in the capital of Iran and other institutes had a minor role in the production of articles. The highest cooperations were also found among the main universities in Tehran.

The analysis of co-authorship network showed that the most influential author, Abduli MA, is from the University of Tehran, which is ranked first among other institutes. This might indicate the existence of a correlation between the ranks of universities and that for authors but which of them leads to another get promoted in ranks, is an issue needs further investigation.

It is foreseeable that to develop more research activities in the field of solid waste in Iran, other universities from other cities of Iran should also involve themselves in solid waste research works and cooperate with the main capital universities using their experiences in this field. Transferring the experiences by capital universities to other institutes and walking toward teamwork activities may increase the number of researches and publications in the field of solid waste engineering and management in Iran. Finally, it was expected the results of this study could be the basis for a better understanding of the international development of researches related to solid waste in Iran.

Acknowledgments This work was supported by the Center for Water Quality Research (CWQR) of Tehran University of Medical Sciences. This support is gratefully acknowledged.

Conflict of interest The authors declare that they have no competing interests. 
Open Access This article is distributed under the terms of the Creative Commons Attribution 4.0 International License (http:// creativecommons.org/licenses/by/4.0/), which permits unrestricted use, distribution, and reproduction in any medium, provided you give appropriate credit to the original author(s) and the source, provide a link to the Creative Commons license, and indicate if changes were made.

\section{Appendix: The search script used for the finding of the solid waste-related documents in Scopus database}

((AUTHKEY("Municipal Solid Waste" OR "Sanitary Landfill" OR "urban solid waste" OR "Leachate Management" OR "Landraising" OR "Institutional Waste" OR "Household Waste" OR "Domestic Waste" OR "waste incineration" OR "waste incinerator" OR "Construction waste" OR "Demolition Waste" OR "Commingled Recyclables waste" OR "Commercial Waste" OR "waste collection" OR "municipal solid waste" OR "solid waste" OR "solid wastes" OR "solid waste disposal" OR "Curb-side Collection" OR "composting" OR "landfill" OR "hospital solid waste" OR "medical solid waste" OR "industrial solid waste" OR "solid waste management" OR "solid waste recycling" OR "solid wasteforms") OR TITLE("Municipal Solid Waste" OR "Sanitary Landfill" OR "urban solid waste" OR "Leachate Management" OR "Landraising" OR "Institutional Waste" OR "Household Waste" OR "Domestic Waste" OR "waste incineration" OR "waste incinerator" OR "Construction waste" OR "Demolition Waste" OR "Commingled Recyclables waste" OR "Commercial Waste" OR "waste collection" OR "municipal solid waste" OR "solid waste" OR "solid wastes" OR "solid waste disposal" OR "Curb-side Collection" OR "composting" OR "landfill" OR "hospital solid waste" OR "medical solid waste" OR "industrial solid waste" OR "solid waste management" OR "solid waste recycling" OR "solid wasteforms") OR ABS("Municipal Solid Waste" OR "Sanitary Landfill" OR "urban solid waste" OR "Leachate Management" OR "Landraising" OR "Institutional Waste" OR "Household Waste" OR "Domestic Waste" OR "waste incineration" OR "waste incinerator" OR "Construction waste" OR "Demolition Waste" OR "Commingled Recyclables waste" OR "Commercial Waste" OR "waste collection" OR "municipal solid waste" OR "solid waste" OR "solid wastes" OR "solid waste disposal" or "Curb-side Collection" OR “composting" OR "landfill” OR "hospital solid waste" OR "medical solid waste" OR "industrial solid waste" OR "solid waste management" OR "solid waste recycling" OR "solid wasteforms")) AND AFFIL("Iran")) AND NOT (KEY("adsorption" OR "sorption" or "desorption”) OR TITLE(“adsorption" OR "sorption" OR “desorption”) OR ABS(“adsorption” OR “sorption” OR “desorption")).

\section{References}

Abduli MA (1995) Solid waste management in Tehran. Waste Manag Res 13:519-531. doi:10.1006/wmre.1995.0050

Abduli MA (1996) Industrial waste management in Tehran. Environ Int 22:335-341. doi:10.1016/0160-4120(96)00020-7

Braun T, Glänzel W, Grupp H (1995) The scientometric weight of 50 nations in 27 science areas, 1989-1993. Part I. All fields combined, mathematics, engineering, chemistry and physics. Scientometrics 33:263-293

Callon M, Courtial J-P, Turner WA, Bauin S (1983) From translations to problematic networks: an introduction to co-word analysis. Soc Sci Inf 22:191-235

Chiu W-T, Ho Y-S (2005) Bibliometric analysis of homeopathy research during the period of 1991 to 2003. Scientometrics 63:3-23

Chiu W-T, Ho Y-S (2007) Bibliometric analysis of tsunami research. Scientometrics 73:3-17

Chokouhmand H (1982) Energy recovery from incineration of Tehran municipal solid waste and its air pollution effects. Energy Convers Manag 22:231-234. doi:10.1016/0196-8904(82) 90047-4

Chuang K-Y, Huang Y-L, Ho Y-S (2007) A bibliometric and citation analysis of stroke-related research in Taiwan. Scientometrics 72:201-212

Colman AM, Dhillon D, Coulthard B (1995) A bibliometric evaluation of the research performance of British university politics departments: publications in leading journals. Scientometrics 32:49-66

Elsevier B.V. Company Scopus Content Overview (2014). http:// www.elsevier.com/online-tools/scopus/content-overview. Accessed 15 Mar 2014

Falagas ME, Pitsouni EI, Malietzis GA, Pappas G (2008) Comparison of PubMed, Scopus, web of science, and Google scholar: strengths and weaknesses. FASEB J 22:338-342

Fang P, Fang JM (1995) A modification of Lotka's function for scientific productivity. Inf Process Manage 31:133-137

Fu H-Z, Ho Y-S, Sui Y-M, Li Z-S (2010) A bibliometric analysis of solid waste research during the period 1993-2008. Waste Manag 30:2410-2417

Fu H-Z, Wang M-H, Ho Y-S (2013) Mapping of drinking water research: a bibliometric analysis of research output during 1992-2011. Sci Total Environ 443:757-765

Fu H-Z, Long X, Ho Y-S (2014) China's research in chemical engineering journals in Science Citation Index Expanded: a bibliometric analysis. Scientometrics 98:119-136

Ho Y-S (2007) Bibliometric analysis of adsorption technology in environmental science. J Environ Prot Sci 1:1-11

Ho Y-S (2014) Classic articles on social work field in Social Science Citation Index: a bibliometric analysis. Scientometrics 98:137-155

Hu J, Ma Y, Zhang L, Gan F, Ho Y-S (2010) A historical review and bibliometric analysis of research on lead in drinking water field from 1991 to 2007. Sci Total Environ 408:1738-1744

Ibáñez A, Larrañaga P, Bielza C (2013) Cluster methods for assessing research performance: exploring Spanish computer science. Scientometrics 97:571-600

Lotka AJ (1926) The frequency distribution of scientific productivity. J Wash Acad Sci 16:317-323 
Ma H, Ho Y-S, Fu H-Z (2011) Solid waste related research in Science Citation Index Expanded. Arch Environ Sci 5:89-100

Nicholls PT (1986) Empirical validation of Lotka's law. Inf Process Manage 22:417-419

Pao ML (1985) Lotka's law: a testing procedure. Inf Process Manag 21:305-320

Patra SK, Bhattacharya P, Verma N (2006) Bibliometric study of literature on bibliometrics. DESIDOC J Libr Inf Technol 26:27-32

R Core Team (2013) R: a language and environment for statistical computing. R Foundation for Statistical Computing, 3.0.2 edn., Vienna, Austria
Tan J, Fu H-Z, Ho Y-S (2014) A bibliometric analysis of research on proteomics in science citation index expanded. Scientometrics 98:1473-1490

Ugolini D, Parodi S, Santi L (1997) Analysis of publication quality in a cancer research institute. Scientometrics 38:265-274

Van Eck NJ, Waltman L (2011) Text mining and visualization using VOSviewer. ISSI Newsl 7(3):50-54

Yang L, Chen Z, Liu T, Gong Z, Yu Y, Wang J (2013) Global trends of solid waste research from 1997 to 2011 by using bibliometric analysis. Scientometrics 96:133-146 